\title{
Surface modification and stability of detonation nanodiamonds in microwave gas discharge
} plasma

Andrei V. Stanishevsky*, Michael J. Walock, Shane A. Catledge

Department of Physics, University of Alabama at Birmingham, Birmingham, AL 35294, USA.

\begin{abstract}
Detonation nanodiamonds (DND), with low hydrogen content, were exposed to microwave plasma generated in pure $\mathrm{H}_{2}, \mathrm{~N}_{2}$, and $\mathrm{O}_{2}$ gases and their mixtures, and investigated using X-ray diffraction (XRD), Fourier Transform Infrared (FTIR), Raman, and X-ray photoelectron spectroscopies. Considerable alteration of the DND surface was observed under the plasma conditions for all used gases, but the diamond structure of the DND particle core was preserved in most cases. The stabilizing effect of $\mathrm{H}_{2}$ in $\mathrm{H}_{2} / \mathrm{N}_{2}$ and $\mathrm{H}_{2} / \mathrm{O}_{2}$ binary gas plasmas on the DND structure and the temperature-dependent formation of various $\mathrm{CNH}_{\mathrm{x}}$ surface groups in $\mathrm{N}_{2}$ and $\mathrm{H}_{2} / \mathrm{N}_{2}$ plasmas were observed and discussed for the first time. DND surface oxidation and etching were the main effects of $\mathrm{O}_{2}$ plasma, whereas the $\mathrm{N}_{2}$ plasma led to DND surfaces rich in amide groups below $1073 \mathrm{~K}$ and nitrile groups at higher temperatures. Noticeable graphitization of the DND core structure was detected only in $\mathrm{N}_{2}$ plasma when the substrate temperature was above $1103 \mathrm{~K}$.
\end{abstract}

Keywords: nanodiamond; microwave; plasma, modification; surface; spectroscopy

* Corresponding author. Tel.: +1 205934 8030; fax: +1 2059348042

E-mail address: astan@uab.edu 


\section{Introduction}

Crystalline diamond nanoparticles prepared by detonation techniques [1] maintain most of the physical properties of bulk diamond and exhibit a rich surface chemistry that makes this material very attractive for a large variety of applications ranging from polishing pastes [2] and fillers in polymer-based composites [3,4] to drug carriers [5,6] and bio-markers [7]. Many of these applications require additional modification of the commercial detonation nanodiamonds (DND) to reduce the agglomerate size and obtain colloids of primary nanocrystals, or to optimize the DND particle surface chemistry for specific purposes [8-10].

Among the different techniques used to modify DND particles, gas discharge plasma treatment has been demonstrated to be an effective tool for the chemical modification of DND surfaces. Several different gases $\left(\mathrm{H}_{2}, \mathrm{O}_{2}, \mathrm{CF}_{4}, \mathrm{SF}_{6}, \mathrm{~N}_{2}\right)$ and plasma generation techniques have been used to de-agglomerate DND particles and improve their dispersibility in water $[11,12]$, change wettability [13] and electric conductivity [14], and introduce new surface functionality $[15,16]$. For example, Gibson et al [12] exposed DND to atmospheric-pressure glow discharge plasma in $\mathrm{O}_{2}$ and $\mathrm{N}_{2}$ gases for different period of times. They found that plasma treatment reduced the size of DND particles. It was also noted that $\mathrm{N}_{2}$ plasma was more efficient than $\mathrm{O}_{2}$ plasma in de-agglomerating DND particles, and short treatment times produced smaller sized particles than longer treatment times. However, the changes in chemical composition of those plasma-treated DND particles were not examined. Kozak et al [17] noted a significant increase in the amount of surface $\mathrm{C}=\mathrm{O}$ groups and disappearance of $\mathrm{C}-\mathrm{H}$ groups after $\mathrm{O}_{2}$ radio-frequency discharge plasma treatment of 5-nm DND particles. The opposite effect was observed by Liu et al [18] when hydrogen plasma was used. Arnault et al [19] determined that substrate temperature plays an important role during DND hydrogenation in $\mathrm{H}_{2}$ microwave plasma. It was shown that 
if the substrate temperature was $793 \mathrm{~K}, \mathrm{C}-\mathrm{O}$ bonds could not transform into $\mathrm{C}-\mathrm{H}$ bonds. During a 15-minute plasma processing time, the amount of oxygen species in DND gradually reduced as temperature increased from $793 \mathrm{~K}$ to $973 \mathrm{~K}$, and all oxygen was removed during that time interval at $973 \mathrm{~K}$. The same group also found that DND particles, when used as a seed layer for growing diamond films in a chemical vapor deposition (CVD) process, exhibit remarkable stability during hydrogen microwave plasma treatment at substrate temperatures of up to $1213 \mathrm{~K}$ $[20]$.

The goal of present work was to further the understanding of microwave gas discharge plasma interaction with DND particles. Surface modification of DND in $\mathrm{N}_{2}, \mathrm{H}_{2} / \mathrm{N}_{2}$, and $\mathrm{H}_{2} / \mathrm{O}_{2}$ gas plasma was studied from the standpoint of achieving better control of surface chemistry and providing DND particles with new functionalities, when compared with only hydrogen or oxygen plasma. Temperature-dependent formation of amide and nitrile groups and a stabilizing effect of $\mathrm{H}_{2}$ on DND structure and surface chemistry in $\mathrm{H}_{2} / \mathrm{N}_{2}$ and $\mathrm{H}_{2} / \mathrm{O}_{2}$ gas mixtures were observed for the first time. X-Ray Diffraction (XRD), Fourier Transform Infrared (FTIR), Raman, and X-ray Photoelectron Spectroscopy (XPS) were used to analyze and explain the chemical and structural changes in DND samples after the plasma processing.

\section{Experiment}

Detonation nanodiamond powders (SINTA Joint-Stock Co, Minsk, Belarus) with a primary crystallite size of $6 \pm 1 \mathrm{~nm}$ and specific surface area of $295 \mathrm{~m}^{2} / \mathrm{g}$, according to the material specifications, were ultrasonically dispersed in de-ionized water, then precipitated in equal amounts $(0.75 \mathrm{mg})$ onto $7 \times 7 \mathrm{~mm}^{2}$ intrinsic silicon substrates $(480 \mu \mathrm{m}$ thickness $)$ and dried in air at $343 \mathrm{~K}$. Silicon substrate was selected due to its stability in microwave plasma and sufficient 
transparency in infrared region of interest. After drying, $70 \pm 30 \mu \mathrm{m}$-thick porous layers of aggregated DND particles were formed. The samples were placed in a $6 \mathrm{~kW} 2.4 \mathrm{GHz}$ Wavemat Microwave Plasma Chemical Vapor Deposition (MWCVD) reactor, and exposed to microwave gas plasmas at $600 \mathrm{~W}$ average power for 45 minutes. In case of individual gas plasmas, the processes were run in $\mathrm{H}_{2}$ (20 Torr or 27 Torr chamber pressure depending on the process, 500 sccm flow rate, substrate temperature self-ramped to $923 \pm 40 \mathrm{~K}$ or to $1013 \pm 40 \mathrm{~K}$ ), $\mathrm{O}_{2}$ (15 Torr / $10 \mathrm{sccm}$ flow, substrate temperature self-ramped to $703 \pm 15 \mathrm{~K}$ ) and $\mathrm{N}_{2}(15$ Torr / $36 \mathrm{sccm}$, substrate temperature self-ramped up to $1048 \pm 25 \mathrm{~K}$ or to $1128 \pm 25 \mathrm{~K}$ ). During the plasma treatment in $\mathrm{O}_{2}$, and $\mathrm{N}_{2}$, hydrogen gas was initially used for 5 minutes to stabilize the plasma and heat the substrate. In case of gas mixtures, the following process parameters were used: $\mathrm{H}_{2} / \mathrm{O}_{2}$ mixture (20 Torr pressure, flow rate $12 \mathrm{sccm}$ and $10 \mathrm{sccm}$, respectively, substrate temperature self-ramped to $1033 \pm 25 \mathrm{~K}$ ) and $\mathrm{H}_{2} / \mathrm{N}_{2}$ mixtures (27 Torr total pressure, flow rate $10 \mathrm{sccm}$ and $36 \mathrm{sccm}$, respectively, substrate temperature self-ramped to $1128 \pm 25 \mathrm{~K})$. The substrate temperature was monitored throughout the process by a two-color Mikron L77LS optical pyrometer. After the process, the samples were cooled down in a low-pressure hydrogen atmosphere.

FTIR spectra (Vertex 70 spectrometer, Bruker Optics) were acquired in transmission mode directly from DND samples on intrinsic silicon substrate, and the substrate background spectra were subtracted. In all cases, the FTIR spectra represented an average of 100 scans recorded with a resolution of $4 \mathrm{~cm}^{-1}$ for each sample.

Philips X'pert MPD thin-film X-ray diffractometer with a $\mathrm{Cu} \mathrm{K \alpha}$ tube $(\lambda=0.15406 \mathrm{~nm})$ operating at $45 \mathrm{kV}$ and $40 \mathrm{~mA}$ was used to determine the crystalline phase composition. The detector was scanned between $20^{\circ}$ and $70^{\circ}$, with a constant take off angle of $5^{\circ}$. Mean crystal size 
was determined using the Lorentzian fitting of diamond (111) peak in the XRD spectrum and Scherrer equation.

Raman microspectroscopy was employed at $532 \mathrm{~nm}$ and $325 \mathrm{~nm}$ excitation wavelengths to determine any plasma-induced peculiarities in DND samples. Raman spectra were collected from several locations across each sample using a Dilor XY system equipped with a $300 \mathrm{~mW}$ solid state laser (Dragon Lasers, China), operating at $\lambda=532 \mathrm{~nm}$ and focused to a $10 \mu \mathrm{m}$ spot size. A Renishaw inVia mapping microRaman spectrometer connected to a Leica microscope and equipped with a $325 \mathrm{~nm}(\mathrm{He}-\mathrm{Cd})$ line-focus laser was used to acquire UV Raman spectra. Wavelength and intensity calibrations were completed by an internal silicon standard using the peak at $520 \mathrm{~cm}^{-1}$. Raman spectra were collected using an 1800 lines/mm grating resulting in resolution $\sim 1 \mathrm{~cm}^{-1}$, with $100 \mathrm{~s}$ integration time per spectrum, and collected using a CCD array. Spectra were processed and analyzed using Wire 3.2 software and peaks were fitted using mixed Gaussian-Lorentzian curves. All measurements were taken in standard laboratory conditions.

A PHI 5000 Versaprobe imaging X-ray photoelectron spectrometer operating a monochromatic, focused Al K $\alpha$ X-ray source $(E=1486.6 \mathrm{eV})$ at $25 \mathrm{~W}$ with a $100 \mu \mathrm{m}$ spot size, was used to determine the chemical bonding in the samples. All samples were grounded. Charge neutralization was provided by a cold cathode electron flood gun and by a low-energy $\mathrm{Ar}^{+}$ion gun operating at $110 \mathrm{~V}$ accelerating voltage and $5 \mathrm{~mA}$ emission current. All measurements were taken under an Ar working pressure of $2 \times 10^{-6} \mathrm{~Pa}$ and room temperature. The system base pressure was $5 \times 10^{-8} \mathrm{~Pa}$. Before surface sputtering, XPS spectra were recorded to avoid the possibility of ion-induced changes in the chemical bonding state of the sample. After sputtering with $500 \mathrm{eV} \mathrm{Ar}^{+}$ions for 3 minutes to remove possible surface contaminations, spectra were 
recorded to confirm the chemical composition. Multipak v9.0 software was used to analyze the resulting spectra.

\section{Results and Discussion}

All DND samples survived both single gas and two-gas plasma treatment for 45 minutes. DND layers were still well-adherent to the substrate which allowed for reasonably easy handling of the material during characterization. X-ray diffraction spectra of the starting and plasmatreated DND did not show the presence of any crystalline or turbostratic graphite phases. Diamond structure also remained mainly intact after exposure to all plasmas as judged by the presence of the (111) peak at $43.9^{\circ}$ (Figure 1, peak intensity was not normalized). The application of different peak fitting procedures (Gaussian and Cauchy functions) and crystal size calculations using the Scherrer equation [21,22] revealed an average size of $5.3 \mathrm{~nm}$ for the diamond crystallites in the original and $\mathrm{H}_{2}$ plasma-treated DND. The exposure of DND to $\mathrm{O}_{2}$ and $\mathrm{N}_{2}$ plasma resulted in a decrease in (111) peak intensity and width. Because equal quantities of DND were used in each experiment, the decrease of intensity may be associated with the loss of material due to enhanced plasma etching. A small decrease in the width of the (111) peak (calculated crystallite size was $5.9 \mathrm{~nm}$ ) could be the result of smaller diamond crystallites experiencing a higher etching rate than the larger crystallites within the DND precipitate.

FTIR spectra collected from DND samples treated in single gas plasmas are shown in Figure 2. The original detonation nanodiamond powder showed distinct absorption bands (Fig.2a) at $1560 \mathrm{~cm}^{-1}$ (C-H or O-H groups), $1640 \mathrm{~cm}^{-1}$ (adsorbed water and C-O-O-H), $1740 \mathrm{~cm}^{-1}(\mathrm{C}=\mathrm{O}$ ), a broad band centered around $3400 \mathrm{~cm}^{-1}(-\mathrm{OH}$ and adsorbed water), broad absorption in the 1400 $\mathrm{cm}^{-1}-1050 \mathrm{~cm}^{-1}$ region (e.g., C-H and O-H bending around 1340, C-O-C at $1258 \mathrm{~cm}^{-1}$, and ester 
C-O at $1115 \mathrm{~cm}^{-1}$ ), and very weak absorbance at $2860 \mathrm{~cm}^{-1}, 2930 \mathrm{~cm}^{-1}$ and $2960 \mathrm{~cm}^{-1}$, associated with stretching vibrations of $\mathrm{CH}_{2}$ and $\mathrm{CH}_{3}$ groups [17].

The $\mathrm{H}_{2}$ plasma treatment at $923 \mathrm{~K}$ substrate temperature led to the pronounced enhancement of the $\mathrm{CH}_{\mathrm{x}}$ absorption bands in $3000 \mathrm{~cm}^{-1}-2800 \mathrm{~cm}^{-1}$ region (Fig.2b) which indicates DND surface termination with hydrogen. The bands have been assigned to symmetric and asymmetric vibrations of $\mathrm{sp}^{3}-\mathrm{CH}_{3}$ (peaks at $2959 \mathrm{~cm}^{-1}$ and $2876 \mathrm{~cm}^{-1}$ ) and $\mathrm{sp}^{3}-\mathrm{CH}_{2}$ (peak at $2930 \mathrm{~cm}^{-1}$ and a possible shoulder at $2852 \mathrm{~cm}^{-1}$ ) groups. The absorption due to $\mathrm{sp}^{2}-\mathrm{CH}_{\mathrm{x}}$ groups was not observed in the experiments. Two small, but noticeable absorption bands, appeared at $1330 \mathrm{~cm}^{-1}$ and 834 $\mathrm{cm}^{-1}$ ( $\mathrm{C}-\mathrm{H}$ bending) and the band at $1740 \mathrm{~cm}^{-1}(\mathrm{C}=\mathrm{O})$ disappeared from the spectrum due to the surface hydrogenation. Disappearance of this characteristic peak at $1740 \mathrm{~cm}^{-1}$ could serve as a proof that the entire volume of DND sample reacted with hydrogen plasma species. Absorption bands at $1640 \mathrm{~cm}^{-1}$ and $3400 \mathrm{~cm}^{-1}$ due to adsorbed water remained practically the same indicating little change in the gas adsorbing properties of $\mathrm{H}_{2}$ plasma-treated DND. This was verified by recording FTIR spectra of DND at temperatures up to $453 \mathrm{~K}$. Both bands gradually decreased with increasing temperature, whereas other absorption bands remained unchanged.

Exposure of DND to $\mathrm{O}_{2}$ or $\mathrm{N}_{2}$ gas plasmas resulted in noticeable $\mathrm{C}-\mathrm{O}$ and $\mathrm{C}-\mathrm{N}$ bonding, respectively (Fig.2c-e). Hydrogen was used at the initial stage of those processes to raise the substrate temperature and stabilize $\mathrm{O}_{2}$ or $\mathrm{N}_{2}$ plasma. Remarkably, $\mathrm{CH}_{\mathrm{x}}$ groups that formed during this initial stage of plasma treatment were not removed by subsequent exposure to oxygen and nitrogen plasma species. $\mathrm{O}_{2}$ gas plasma treatment (Fig.2c) re-oxidized the DND surface as evident from the enhancement of absorption due to $\mathrm{C}=\mathrm{O}$ groups $\left(1746 \mathrm{~cm}^{-1}\right)$. The intensity of this band in the FTIR spectrum became relatively stronger than it was in the original DND. On the contrary, $\mathrm{N}_{2}$ gas plasma treatment (Fig.2d,e) led to the appearance of $-\mathrm{C} \equiv \mathrm{N}\left(2160 \mathrm{~cm}^{-1}-\right.$ 
$2190 \mathrm{~cm}^{-1}$ ), and other $\mathrm{CNH}_{\mathrm{x}}$ groups (in $1580 \mathrm{~cm}^{-1}-1100 \mathrm{~cm}^{-1}$ region), depending on the substrate temperature. It was suggested that the lack of $\mathrm{C}=\mathrm{O}$ groups in $\mathrm{N}_{2}$ plasma-treated DND was associated with $\mathrm{H}_{2}$ plasma pre-treatment, and thus nitrogen plasma species interacted with mainly oxygen-free DND surface. It was observed that even for relatively small variations in the substrate temperature the result of $\mathrm{N}_{2}$ plasma modification of DND surface was very different. For example, the FTIR spectrum of $\mathrm{N}_{2}$ plasma-treated DND in Fig.2d (substrate temperature $1048 \pm 25 \mathrm{~K}$ ) demonstrated strong bands at $1564 \mathrm{~cm}^{-1}$ and $1254 \mathrm{~cm}^{-1}$ (due to coupled bend-stretch oscillations of C-N-H in the amide group), and other new bands at $1461 \mathrm{~cm}^{-1}(\mathrm{~N}-\mathrm{H}$ in plane bending), $1401 \mathrm{~cm}^{-1}, 1305 \mathrm{~cm}^{-1}, 1196 \mathrm{~cm}^{-1}, 1137 \mathrm{~cm}^{-1}$ (possibly N-H and C-N stretching in different configurations) and very weak absorption around $2174 \mathrm{~cm}^{-1}$ (nitrile group) [23,24]. However, at a slightly higher substrate temperature $(1128 \pm 25 \mathrm{~K})$, only the nitrile bands around $2160 \mathrm{~cm}^{-1}$ dominated (Fig.2e). The formation of nitrile groups can be associated with a sharply increased efficiency of molecular nitrogen dissociation when the substrate temperature exceeds a certain threshold. $\mathrm{CH}_{\mathrm{x}}$ absorption bands became broader and weaker in the latter FTIR spectrum, which could be related to the enhanced etching of DND surface layers by atomic nitrogen under these process conditions. A local increase in the concentration of carbon and nitrogen species can lead to the formation of nitrogen-enriched amorphous carbon layer within the porous DND precipitate.

Significant differences in the plasma-treatment results were noted when the DND was exposed to binary gas mixtures, either $\mathrm{H}_{2} / \mathrm{O}_{2}$ or $\mathrm{H}_{2} / \mathrm{N}_{2}$. First, when hydrogen was present, the effect of both $\mathrm{O}_{2}$ and $\mathrm{N}_{2}$ gases on DND surface modification was much less. Second, hydrogen seemed to be efficient at higher substrate temperatures in creating more $\mathrm{sp}^{3}-\mathrm{CH}_{3}$ groups and stabilizing the surface against oxygen and nitrogen plasma species. Figure 3 shows the 
comparison between FTIR spectra of DND treated in single and binary gas plasmas. One difference between the spectra of $\mathrm{H}_{2}$ plasma-treated DND in Fig.2b and Fig.3a is the relatively higher ratio of $\mathrm{sp}^{3}-\mathrm{CH}_{3}$ to $\mathrm{sp}^{3}-\mathrm{CH}_{2}$ groups. This can be a result of the higher reactivity of hydrogen species at higher substrate temperatures. There were almost no changes in the FTIR spectra of $\mathrm{H}_{2} / \mathrm{O}_{2}$ or $\mathrm{H}_{2} / \mathrm{N}_{2}$ plasma-treated DND when compared with the pure $\mathrm{H}_{2}$ sample, except the appearance of a strong nitrile absorption band at $2177 \mathrm{~cm}^{-1}$ in $\mathrm{H}_{2} / \mathrm{N}_{2}$ plasma-treated DND [25]. FTIR spectra of $\mathrm{N}_{2}$ and $\mathrm{H}_{2} / \mathrm{N}_{2}$ plasma-treated samples in Fig.3d,e were almost identical, which indicates that nitrile groups formation, above the threshold substrate temperature, seems to be independent of the presence of $\mathrm{H}_{2}$. Formation of less reactive $\mathrm{HN}_{2}{ }^{+}$and an increased ratio of $\mathrm{H} / \mathrm{N}$ atoms were proposed in this case [26]. This could increase the etching rate of non-diamond constituents while simultaneously reducing the re-deposition and less affecting the DND core structure. Furthermore, annealing of $\mathrm{N}_{2}$ and $\mathrm{H}_{2} / \mathrm{N}_{2}$ plasma-treated DND in air led to the disappearance of nitrile groups above $473 \mathrm{~K}$. This indicates that the nitrogen-rich re-deposited layer may have a polymeric-like structure. FTIR spectra similar to those of the original DND were obtained after annealing these samples at $673 \mathrm{~K}$.

Several possible competing processes involved in the observed trends include the preferential etching of $\mathrm{sp}^{2}$-bonded carbon and DND core stabilization by hydrogen [9, 27], surface etching and removal of reaction products by oxygen, and temperature-dependent etching of DND and formation of polymeric-like fragments by nitrogen plasma species. The formation of, perhaps less reactive to $\mathrm{DND}, \mathrm{OH}_{\mathrm{x}}$ and $\mathrm{NH}_{\mathrm{y}}$ radicals in binary gas plasmas could also lead to a smaller effect of individual gases in the mixture. Besides, it is reasonable to assume that the motion of plasma species was limited within a porous DND precipitate, even though it was a few tens of micrometers thick, leading to the extended residence time of plasma species. In the case 
of nitrogen plasma this may have created favorable conditions for the temperature-dependent redeposition and plasma polymerization of $\mathrm{CN}_{\mathrm{x}} \mathrm{H}_{\mathrm{y}}$-reach compounds on the DND surface.

As a companion technique to FTIR, Raman spectroscopy revealed that microwave plasma treatment had, indeed, relatively small effects on the DND core structure for most of the process parameters used. Raman spectra (532 nm laser excitation) recorded from the original and singlegas plasma-treated DND are shown in Figure 4. Based on literature [28], an optimized fitting procedure of the spectra includes five bands $\left(1324 \mathrm{~cm}^{-1}, 1370 \mathrm{~cm}^{-1}, 1480 \mathrm{~cm}^{-1}, 1550 \mathrm{~cm}^{-1}, 1594\right.$ $\left.\mathrm{cm}^{-1}\right)$ in Fig.4a-d, and six bands $\left(1583 \mathrm{~cm}^{-1}\right.$ and $1610 \mathrm{~cm}^{-1}$ instead of single $1594 \mathrm{~cm}^{-1}$ band) in Fig.4e. The ratio $\boldsymbol{R}_{p a}$ of the peak area at $1324 \mathrm{~cm}^{-1}$ (assigned to $\mathrm{sp}^{3}$-bonds in ND) to a sum of $1550 \mathrm{~cm}^{-1}$ and $1594 \mathrm{~cm}^{-1}$ peaks (assigned to $\mathrm{sp}^{2}$-bonded small carbon clusters and G-band of graphite) serves as a possible indicator of structural changes in DND particles. The values of $\boldsymbol{R}_{p a}$ for Raman spectra in Fig.4a-e were obtained as 0.87, 0.69, 0.63, 0.46, and 0.43, respectively, with the higher number corresponding to a larger amount of $\mathrm{sp}^{3}$-bonded phases. This data suggests that $\mathrm{N}_{2}$ plasma treatment led to somewhat larger $\mathrm{sp}^{2}$-bonded carbon content in DND samples, especially at higher temperature, and the $\mathrm{H}_{2}$ plasma had the least effects.

The observed trend was in good agreement with the results of UV (excitation wavelength $325 \mathrm{~nm}$ ) Raman spectroscopy (Figure 5). A peak at $1326 \mathrm{~cm}^{-1}$ is a characteristic feature of crystalline DND particles in UV Raman spectra, while a broad peak centered at $1646 \mathrm{~cm}^{-1}$ is the superposition of Raman bands of $\mathrm{sp}^{2}$-bonded carbon, $-\mathrm{OH}$ and $\mathrm{C}=\mathrm{O}$ groups [29]. There was little difference in UV Raman spectra of the original, $\mathrm{H}_{2}$ and $\mathrm{O}_{2}$ plasma-treated DND samples. In $\mathrm{N}_{2}$ plasma-treated samples, the intensity of $1326 \mathrm{~cm}^{-1}$ peak is reduced when compared with the peak at $1610 \mathrm{~cm}^{-1}$ (Fig.5d). Raman spectrum in Fig.5e (high-temperature $\mathrm{N}_{2}$ plasma-treated DND) showed a strong narrow peak at $1581 \mathrm{~cm}^{-1}$ and a $1400 \mathrm{~cm}^{-1}$ peak. The first peak is a 
characteristic feature in graphitic materials, and the second peak can be associated with a disorder-induced band in the aromatic $\mathrm{sp}^{2}$-carbon clusters $[28,30]$, perhaps at the interface between the diamond and graphitic regions. This indicates significant $\mathrm{sp}^{2}$-bonded carbon content when DND samples are treated in an $\mathrm{N}_{2}$ plasma at $1128 \pm 25 \mathrm{~K}$. Raman spectrum of $\mathrm{H}_{2} / \mathrm{N}_{2}$ plasma-treated DND was identical to that of $\mathrm{N}_{2}$ DND sample. However, neither $532 \mathrm{~nm}$ nor 325 $\mathrm{nm}$ Raman spectroscopy registered the presence of C-N bonds in $\mathrm{N}_{2}$ plasma-treated DND. Possible reasons for this may be the low content of $\mathrm{CN}_{\mathrm{x}} \mathrm{H}_{\mathrm{y}}$ groups, their weak Raman activity [31], and localized sample heating, especially in the formed $\mathrm{sp}^{2}$-rich thin layer, during the Raman experiments $[32,33]$. It should be emphasized that the nitrile absorption band in FTIR spectra appears strong only due to the reduced peaks from other bands.

XPS data support FTIR and Raman spectroscopy results on the surface modification of plasma-treated DND powders. Table 1 provides a summary of XPS spectral features for all plasma-treated DND. The C/N/O ratios in Table 1 were calculated from C1s, O1s, and N1s peaks in XPS survey spectra shown in Figure 6, and other data were taken from the high-resolution scans of those peaks. It can be seen that plasma treatment in individual gases significantly changes the composition of DND, whereas binary plasmas provided intermediate results. On the other hand, the main peak position of plasmon loss spectra was observed around $34.2-34.7 \mathrm{eV}$ ( $\sigma$-plasmon in bulk diamond) for almost all samples, which confirm their diamond structure, except the high-temperature $\mathrm{N}_{2}$ plasma-treated sample showing graphitic features [34,35]. High resolution $\mathrm{C} 1 \mathrm{~s}$ core level (before and after sputtering) and plasmon loss spectra of DND treated in single gas plasmas are shown in Figure 6. XPS data indicate the formation of noticeable amount of $\mathrm{sp}^{2}$-bonded carbon only in $\mathrm{N}_{2}$ plasma-treated DND at higher temperature (Fig.6e), which correlates with the results from Raman spectroscopy. C1s core level peak in this sample is 
centered at $285.0 \mathrm{eV}$ with small contributions at approximately $286.0 \mathrm{eV}(-\mathrm{C} \equiv \mathrm{N})$ and $287.4 \mathrm{eV}$ ( $\mathrm{C}-\mathrm{O}$ in adsorbed $\mathrm{CO}_{2}$ ). The peak position at $285 \mathrm{eV}$ can be related to either $\mathrm{sp}^{3}$-bonded carbon or $\mathrm{C}-\mathrm{H}$ bonds or bond deformation in very small $\mathrm{sp}^{2}$-bonded carbon clusters [36]. The latter feature can also be the reason for the appearance of $1400 \mathrm{~cm}^{-1}$ peak in UV Raman spectrum of this sample. Plasmon loss spectrum of this sample exhibits maxima at $27.5 \mathrm{eV}(\pi+\sigma$ plasmon) and $6.5 \mathrm{eV}\left(\pi-\pi^{*}\right.$ transition) which are characteristic to graphitic structure. A relatively flat plateau above $27.5 \mathrm{eV}$ can still indicate some overlap with $\sigma$-plasmon in very small DND crystallites [34,35]. Furthermore, a weak but resolved N1s peak is centered around $398.1 \mathrm{eV}$ in this sample (Fig.6e, inset), which can be assigned to the both nitrogen bonded to three carbon atoms in $\mathrm{sp}^{2}$-configuration and a terminating $-\mathrm{C} \equiv \mathrm{N}$ bonding configuration [37]. The DND sample treated in $\mathrm{N}_{2}$ at lower temperature exhibited a broad C1s peak (Fig.6d) and a weak but broad N1s peak between $397.4 \mathrm{eV}$ and $400.0 \mathrm{eV}$ (Fig.6d, inset) due to the presence of various $\mathrm{CN}_{\mathrm{x}} \mathrm{H}_{\mathrm{y}}$ bond configurations. This sample had the highest nitrogen content (4.8 at\%). The plasmon loss spectrum of this sample shows the characteristic maximum at $34.5 \mathrm{eV}$ which is similar to plasmon loss spectra of all other DND samples except the more graphitic hightemperature $\mathrm{N}_{2}$ plasma-treated one. Interestingly, the high-temperature $\mathrm{H}_{2} / \mathrm{N}_{2}$ plasma-treated DND sample revealed almost the same C1s and plasmon loss spectra (not shown) whereas its FTIR spectrum (Fig.3d) was similar to that of high-temperature $\mathrm{N}_{2}$ plasma-treated DND. Such difference suggests that hydrogen prevents, at least partially, the graphitization of DND in $\mathrm{H}_{2} / \mathrm{N}_{2}$ plasma, and the formation of nitrile groups is stimulated at a higher substrate temperature.

The shape and width of C1s core level in binding energy spectra in Fig.6a-d confirmed the presence of multiple chemical bonding types that fit into the typical binding energy ranges for C$\mathrm{H}(285 \mathrm{eV}-286 \mathrm{eV}), \mathrm{C}-\mathrm{N}(285.5 \mathrm{eV}-286.9 \mathrm{eV})$, and $\mathrm{C}-\mathrm{O}(286 \mathrm{eV}-289 \mathrm{eV})$ groups in 
different combinations [38,39]. However, the fitting and quantitative analysis of these spectra is complicated by the complexity of bond configurations, and thus the results are discussed rather qualitatively. Although $\mathrm{C} 1 \mathrm{~s}$ peak at $285 \mathrm{eV}$ is usually assigned to $\mathrm{sp}^{3} \mathrm{C}-\mathrm{C}$ bonding, the contributions from $\mathrm{CH}_{\mathrm{x}}(285 \mathrm{eV}-286 \mathrm{eV})$ and $\mathrm{sp}^{2} \mathrm{C}-\mathrm{C}(284.3 \mathrm{eV})$ bonding, along with rough surface of DND samples and local electric charge transfer, made the determination of $\mathrm{sp}^{3} / \mathrm{sp}^{2}$ ratio not possible. On the other hand, the observed trends in the C1s peak position and shape correlate with other results on the composition and dominating surface groups in plasma-treated DND, such as the reduction or increase in C-O functional groups in $\mathrm{H}_{2}$ and $\mathrm{O}_{2}$ plasma-treated DND (Fig.6b and Fig.6c, respectively), or the graphitization and loss of surface functional groups in high-temperature $\mathrm{N}_{2}$ plasma-treated DND. Sputtering of the samples with $500 \mathrm{eV} \mathrm{Ar}^{+}$ ions for 1 minute partially removed the weakly-bonded surface functional groups, reduced the amounts of nitrogen- and oxygen-rich surface groups, and revealed a better defined C1s peak from DND particle core around $285 \mathrm{eV}$ in the original, $\mathrm{H}_{2}$, and $\mathrm{O}_{2}$ plasma-treated samples. There was less change in C1s spectrum of lower-temperature $\mathrm{N}_{2}$ plasma-treated DND, and very little change in the $\mathrm{C}$ 1s peak after sputtering high-temperature $\mathrm{N}_{2}$ plasma-treated DND. This can be due to the presence of a relatively thick $\mathrm{CN}_{\mathrm{x}} \mathrm{H}_{\mathrm{y}}$ re-deposited layer, which would take a longer time to remove.

\section{Conclusions}

In summary, detonation nanodiamond particles can be efficiently modified under the microwave plasma conditions in single and binary $\mathrm{H}_{2}, \mathrm{O}_{2}$, and $\mathrm{N}_{2}$ gas plasmas. The result of such modification depended on the type of plasma species and substrate temperature. DND surface hydrogenation and oxidation were main effects of $\mathrm{H}_{2}$ and $\mathrm{O}_{2}$ plasma, respectively, whereas $\mathrm{N}_{2}$ 
plasma led to the formation of various $\mathrm{CN}_{\mathrm{x}} \mathrm{H}_{\mathrm{y}}$ functional groups below $1073 \mathrm{~K}$ and nitrile at higher temperatures. Noticeable graphitization of DND was observed only in $\mathrm{N}_{2}$ plasma at a substrate temperature above $1103 \mathrm{~K}$. Partial re-deposition of etched species and plasma polymerization effects in $\mathrm{N}_{2}$ plasma were proposed to lead to the formation of nitrogen-rich amorphous surface layer on DND core. It was observed for the first time that hydrogen in $\mathrm{H}_{2} / \mathrm{N}_{2}$ and $\mathrm{H}_{2} / \mathrm{O}_{2}$ binary gas plasmas tends to hinder the effects of oxygen and nitrogen plasma species, respectively. These results demonstrated a possibility for broad range tuning of the surface functionality of DND particles, without considerable alteration of their initial structure, with a reasonable level of control by using different gas compositions in microwave discharge plasma.

\section{Acknowledgements}

The authors would like to thank Dr. Stanislaw Mitura for providing DND powders, Dr. Molly Gentleman for the help with UV Raman spectroscopy, and Inessa Stanishevskaya for graphics design. FTIR and XPS spectroscopy instruments used in this research were supported by the National Institutes of Health - National Center for Research Resources (NIH/NCRR) Grant S10RR023388 and by NSF Grant DRM-0922910, respectively.

\section{References}

1. N.R. Greiner, D.S. Phillips, J.D. Johnson, F. Volk, Diamonds in detonation soot, Nature 333 (1988) 440-442.

2. A.S. Artemov, Polishing nanodiamonds, Phys. Solid State 46 (2004) 687-695. 
3. O. Shenderova, C. Jones, V. Borjanovic, S. Hens, G. Cunningham, S. Moseenkov, V. Kuznetsov, G. McGuire, Detonation nanodiamond and onion-like carbon: applications in composites, Phys. Stat. Sol. A 205 (2008) 2245-2251.

4. K.D. Behler, A. Stravato, V. Mochalin, G. Korneva, G. Yushin, Y. Gogotsi, NanodiamondPolymer Composite Fibers and Coatings, ACS Nano 3 (2009) 363-369.

5. R.A. Shimkunas, E. Robinson, R. Lam, S. Lu, X. Xu, X.Q. Zhang, H. Huang, E. Osawa, D. Ho, Nanodiamond-insulin complexes as pH-dependent protein delivery vehicles, Biomaterials 30 (2009) 5720-5728.

6. T. Burleson, N. Yusuf, A. Stanishevsky, Surface Modification of Nanodiamonds for Biomedical Application, J. Achiev. Mater. Manuf. Eng. 37 (2009) 258-263.

7. C.C. Fu, H.Y. Lee, K. Chen, T.S. Lim, H.Y. Wu, P.K. Lin, P.K. Wei, P.H. Tsao, H.C. Chang, W. Fann, Characterization and application of single fluorescent nanodiamonds as cellular biomarkers, Proc. Natl. Acad. Sci. U.S.A. 104 (2007) 727-732.

8. A. Krueger, D. Lang, Functionality is key: Recent progress in the surface modification of nanodiamond, Adv. Funct. Mater. 22 (2012) 890-906.

9. V.Yu. Dolmatov, Detonation-synthesis nanodiamonds: synthesis, structure, properties and applications, Russian Chem. Rev. 76 (2007) 339-360.

10. A. Kruger, F. Kataoka, M. Ozawa, T. Fujino, Y. Suzuki, A.E. Alesenskii, A.Y. Vul, E. Osawa, Unusually tight aggregation in detonation nanodiamond: Identification and disintegration, Carbon 43 (2005) 1722-1730.

11. Q. Yu, Y.J. Kim, H. Ma, Plasma treatment of diamond nanoparticles for dispersion improvement in water, Appl. Phys. Lett. 88 (2006) 231503. 
12. N. Gibson, O. Shenderova, T.J.M. Luo, S. Moseenkov, V. Bondar, A. Puzyr, K. Purtov, Z. Fitzgerald, D.W. Brenner, Colloidal stability of modified nanodiamond particles, Diamond Relat. Mater. 18 (2009) 620-626.

13. J.H.C. Yang, K. Teii, Mechanism of enhanced wettability of nanocrystalline diamond films by plasma treatment, Thin Solid Films 520 (2012) 6566-6570.

14. S. Su, J. Li, V. Kundrát, A.M. Abbot, H. Ye, Hydrogen-passivated detonation nanodiamond: An impedance spectroscopy study, Diamond Relat. Mater. 24 (2012) 49-53.

15. M.A. Ray, O. Shenderova, W. Hook, A. Martin, V. Grishko, T. Tyler, G.B. Cunningham, G. McGuire, Cold plasma functionalization of nanodiamond particles, Diamond Relat. Mater. 15 (2006) 1809-1812.

16. H.A. Girard, J.C. Arnault, S. Perruchas, S. Saada, T. Gacoin, J.-P. Boilot, P. Bergonzo, Hydrogenation of nanodiamonds using MPCVD: A new route toward organic functionalization, Diamond Relat. Mater. 19 (2010) 1117-1123.

17. H. Kozak, Z. Remes, J. Houdkova, S. Stehlik, A. Kromka, B. Rezek, Chemical modifications and stability of diamond nanoparticles resolved by infrared spectroscopy and Kelvin force microscopy, J. Nanoparticle Res. 15 (2013) 1568.

18. X. Liu, Z. Yu, Q. Wei, G. Wen, X. Duan, X. You, Modification of polycrystalline nanodiamonds by using periodic magnetic field enhanced hydrogen plasma and the application on nanogrinding of thin film magnetic head, Colloid. Surf. A 416 (2013) 9-15.

19. J.C. Arnault, T. Petit, H. Girard, A. Chavanne, C. Gesset, M. Sennour, and M. Chaigneau, Surface chemical modifications and surface reactivity of nanodiamonds hydrogenated by CVD plasma, Phys. Chem. Chem. Phys. 13 (2011) 11481-11487. 
20. J.C. Arnault, S. Saad, M. Nesladek, O.A. Williams, K. Haenen, P. Bergonzo, E. Osawa, Diamond nanoseeding on silicon: Stability under $\mathrm{H}_{2}$ MPCVD exposures and early stages of growth, Diamond Relat. Mater. 17 (2008) 1143-1149.

21. S.V. Tsybulya, S.V. Cherepanova, G.N. Kryukova, Full profile analysis of X-ray diffraction patterns for investigation of nanocrystalline systems, in Diffraction analysis of the microstructure of materials, Eds. E.J. Mittemeijer, P. Scardi, Springer, Berlin, 2004, pp.93123.

22. B. Palosz, E. Grzanka, C. Pantea, T.W. Zerda, Y. Wang, J. Gubicza, T. Ungár, Microstructure of nanocrystalline diamond powders studied by powder diffractometry, J. Appl. Phys. 97 (2005) 064316.

23. P.J. Larkin, Infrared and Raman spectroscopy; Principles and spectral interpretation, Elsevier, Oxford, 2011, p.69.

24. D. Lin-Vien, N.B. Colthup, W.G. Fateley, J.G. Grasselli, The handbook of infrared and Raman characteristic frequencies of organic molecules, Academic Press, London, 1991, pp.167-169.

25. A. Majumdar, G. Das, K.R. Basvani, J. Heinicke, R. Hippler, Role of Nitrogen in the Formation of HC-N Films by $\mathrm{CH}_{4} / \mathrm{N}_{2}$ Barrier Discharge Plasma: Aliphatic Tendency, J. Phys. Chem. B 113 (2009) 15734.

26. E. Tatarova, V. Guerra, J. Henriques, C.M. Ferreira, Nitrogen dissociation in low-pressure microwave, J. Phys. Conf. Ser. 71 (2007) 012010.

27. Z. Shpilman, I. Gouzman, E. Grossman, R. Akhvlediani, A. Hoffman, Hydrogen plasma and atomic oxygen treatments of diamond: chemical versus morphological aspects, Appl. Phys. Lett. 92 (2008) 234103. 
28. A.C. Ferrari, J. Robertson, Raman spectroscopy of amorphous, nanostructured, diamondlike carbon, and nanodiamond, Phil. Trans. R. Soc. Lond. A 362 (2004) 2477-2512.

29. V. Mochalin, S. Osswald, Y. Gogotsi, Contribution of functional groups to the Raman spectrum of nanodiamond powders, Chem. Mater. 21 (2009) 273-279.

30. A.C. Ferrari, J. Robertson, Resonant Raman spectroscopy of disordered, amorphous, and diamondlike carbon, Phys. Rev. B 64 (2001) 075414.

31. A.C. Ferrari, S.E. Rodil, J. Robertson, Interpretation of infrared and Raman spectra of amorphous carbon nitrides, Phys. Rev. B 67 (2003) 155306.

32. M. Liu, K.L. Jiang, Q.Q. Li, H.T. Yang, S.S. Fan, Laser-induced high local temperature in carbon nanotube, Solid State Phenom. 121-123 (2007) 331-336.

33. J. Vlček, P. Fitl, M. Vrňata, L. Fekete, A. Taylor, F. Fendrych, UV-laser treatment of nanodiamond seeds - a valuable tool for modification of nanocrystalline diamond films properties, J. Phys. D: Appl. Phys. 46 (2013) 035307.

34. X. Liu, F. Klauser, N. Memmel, E. Bertel, T. Pichler, M. Knupfer, A. Kromka, D. Steinmüller-Nethl, Spectroscopic studies of nanocrystalline diamond materials, Diam. Relat. Mater. 16 (2007) 1463-1470.

35. S. Zeppilli, J.C. Arnault, C. Gesset, P. Bergonzo, R. Polini, Thermal stability and surface modifications of detonation diamond nanoparticles studied with X-ray photoelectron spectroscopy, Diam. Relat. Mater. 19 (2010) 846-853.

36. Yu.V. Butenko, S. Krishnamurthy, A. K. Chakraborty, V.L. Kuznetsov, V.R. Dhanak, M.R.C. Hunt, L. Šiller, Photoemission study of onionlike carbons produced by annealing nanodiamonds, Phys. Rev. B 71 (2005) 075420. 
37. J. C. Sánchez-López, C. Donnet, F. Lefèbvre, C. Fernández-Ramos and A. Fernández, Bonding Structure in Amorphous Carbon Nitride: A Spectroscopic and Nu-clear Magnetic Resonance Study, J. Appl. Phys. 90 (2001) 675-681.

38. Sh. Michaelson, R. Akhvlediani, T. Petit, H.A. Girard, J.C. Arnault, A. Hoffman, HR-EELS study of hydrogen bonding configuration, chemical and thermal stability of detonation nanodiamond films, Appl. Surf. Sci. 305 (2014) 160-166.

39. S. Torrengo, R. Canteri, R. Dell'Anna, L. Minati, A. Pasquarelli, G. Speranza, XPS and ToF-SIMS investigation of nanocrystalline diamond oxidized surfaces, Appl. Surf. Sci. 276 (2013) 101-111. 
Table 1. Summary of XPS data on original and microwave plasma-treated DND particles

\begin{tabular}{|c|c|c|c|c|c|}
\hline $\begin{array}{l}\text { Material and } \\
\text { process }\end{array}$ & $\begin{array}{c}\mathrm{C} / \mathrm{O} / \mathrm{N} \\
\text { ratio, at\% }\end{array}$ & C1s, eV & $\begin{array}{c}\text { Plasmon Loss } \\
\Delta \mathrm{E}, \mathrm{eV}\end{array}$ & N1s,eV & O1s, eV \\
\hline (a) original ND & $90.1 / 7.3 / 2.6$ & $287.1 ; 287.9$ & 34.7 & 401.0 & 533.4 \\
\hline $\begin{array}{l}\text { (b) } \mathrm{H}_{2} \text { plasma } \\
\mathrm{T}_{\mathrm{s}}=923 \pm 10 \mathrm{~K}\end{array}$ & $94.2 / 4.8 / 1.0$ & $\begin{array}{c}285.9 ; 286.5 ; \\
287.4\end{array}$ & 34.5 & 400.0 trace & 532.3 \\
\hline $\begin{array}{l}\text { (c) } \mathrm{O}_{2} \text { plasma } \\
\mathrm{T}_{\mathrm{S}}=703 \pm 10 \mathrm{~K}\end{array}$ & $\begin{array}{c}73.7 / 21.6 / 2 . \\
4\end{array}$ & $285.8 ; 287.8$ & 34.2 & 401.0 trace & $\begin{array}{l}532.7 \\
530.9\end{array}$ \\
\hline $\begin{array}{l}\text { (d) } \mathrm{N}_{2} \text { plasma } \\
\mathrm{T}_{\mathrm{s}}=1048 \pm 25 \mathrm{~K}\end{array}$ & $84.6 / 8.0 / 4.7$ & $\begin{array}{c}285.9 ; 287.0 ; \\
287.6\end{array}$ & 34.2 & $\begin{array}{c}397.4-400.0 \\
\text { Broad peak }\end{array}$ & $\begin{array}{l}532.0 \\
530.9\end{array}$ \\
\hline $\begin{array}{l}\text { (e) } \mathrm{N}_{2} \text { plasma } \\
T_{\mathrm{S}}=1128 \pm 25 \mathrm{~K}\end{array}$ & $94.2 / 3.0 / 2.8$ & $\begin{array}{c}285.0 ; 286.0 ; \\
287.4\end{array}$ & 6.5 and 27.5 & 398.1 & 532.4 \\
\hline $\begin{array}{l}\text { (f) } \mathrm{H}_{2} / \mathrm{N}_{2} \text { plasma, } \\
\mathrm{T}_{\mathrm{s}}=1128 \pm 25 \mathrm{~K}\end{array}$ & $91.7 / 4.9 / 3.4$ & $\begin{array}{l}285.8 ; 286.4 ; \\
287.4\end{array}$ & 34.4 & 398.2 & 532.4 \\
\hline $\begin{array}{l}\text { (g) } \mathrm{H}_{2} / \mathrm{O}_{2} \text { plasma, } \\
\mathrm{T}_{\mathrm{s}}=1033 \pm 25 \mathrm{~K}\end{array}$ & $89.4 / 9.4 / 1.2$ & $\begin{array}{c}285.9 ; 286.6 ; \\
287.8\end{array}$ & 34.5 & 400.0 trace & 532.5 \\
\hline
\end{tabular}




\section{FIGURE CAPTIONS}

Figure 1. X-ray diffraction patterns of (a) original detonation nanodiamond (DND) powder, and DND exposed to microwave gas plasma of (b) $\mathrm{H}_{2}$ at $\mathrm{T}_{\mathrm{s}}=923 \pm 10 \mathrm{~K}$, (c) $\mathrm{O}_{2}$ at $\mathrm{T}_{\mathrm{s}}=703 \pm 10 \mathrm{~K}$, (d) $\mathrm{N}_{2}$ at $\mathrm{T}_{\mathrm{s}}=1048 \pm 25 \mathrm{~K}$, and (e) $\mathrm{N}_{2}$ at $\mathrm{T}_{\mathrm{s}}=1128 \pm 25 \mathrm{~K}$.

Figure 2. FTIR spectra of (a) original detonation nanodiamond (DND) powder, and DND exposed to microwave gas plasma of (b) $\mathrm{H}_{2}$ at $\mathrm{T}_{\mathrm{s}}=923 \pm 10 \mathrm{~K}$, (c) $\mathrm{O}_{2}$ at $\mathrm{T}_{\mathrm{s}}=703 \pm 10 \mathrm{~K}$, (d) $\mathrm{N}_{2}$ at $\mathrm{T}_{\mathrm{s}}=1048 \pm 25 \mathrm{~K}$, and (e) $\mathrm{N}_{2}$ at $\mathrm{T}_{\mathrm{s}}=1128 \pm 25 \mathrm{~K}$. Expanded view of $\mathrm{CH}_{\mathrm{x}}$ absorption bands in 2800 $\mathrm{cm}^{-1}-3000 \mathrm{~cm}^{-1}$ infrared region is shown on the right.

Figure 3. FTIR spectra of DND exposed to microwave gas plasma of (a) $\mathrm{H}_{2}$ at $\mathrm{T}_{\mathrm{s}}=1013 \pm 10 \mathrm{~K}$, (b) $\mathrm{H}_{2} / \mathrm{O}_{2}$ at $\mathrm{T}_{\mathrm{s}}=1033 \pm 25 \mathrm{~K}$, (c) $\mathrm{O}_{2}$ at $\mathrm{T}_{\mathrm{s}}=703 \pm 10 \mathrm{~K}$, (d) $\mathrm{N}_{2}$ at $\mathrm{T}_{\mathrm{s}}=1128 \pm 25 \mathrm{~K}$, and (e) $\mathrm{H}_{2} / \mathrm{N}_{2}$ at $\mathrm{T}_{\mathrm{S}}=1128 \pm 25 \mathrm{~K}$. Expanded view of $\mathrm{CH}_{\mathrm{x}}$ absorption bands in $2800 \mathrm{~cm}^{-1}-3000 \mathrm{~cm}^{-1}$ infrared region is shown on the right.

Figure 4. Raman spectra $(532 \mathrm{~nm})$ of (a) original DND powder, and DND exposed to microwave gas plasma of (b) $\mathrm{H}_{2}$ at $\mathrm{T}_{\mathrm{s}}=923 \pm 10 \mathrm{~K}$, (c) $\mathrm{O}_{2}$ at $\mathrm{T}_{\mathrm{s}}=703 \pm 10 \mathrm{~K}$, (d) $\mathrm{N}_{2}$ at $\mathrm{T}_{\mathrm{s}}=$

$1048 \pm 25 \mathrm{~K}$, and (e) $\mathrm{N}_{2}$ at $\mathrm{T}_{\mathrm{s}}=1128 \pm 25 \mathrm{~K}$. The lines at $1332 \mathrm{~cm}^{-1}$ and $1581 \mathrm{~cm}^{-1}$ are provided to guide the eye. Peak fitting for original DND (left), and DND treated in $\mathrm{N}_{2}$ plasma at temperature $1128 \pm 25 \mathrm{~K}$ (right) are shown below. 
Figure 5. UV Raman spectra $(325 \mathrm{~nm})$ of (a) original detonation nanodiamond (DND) powder, and DND exposed to microwave gas plasma of (b) $\mathrm{H}_{2}$ at $\mathrm{T}_{\mathrm{s}}=923 \pm 10 \mathrm{~K}$, (c) $\mathrm{O}_{2}$ at $\mathrm{T}_{\mathrm{s}}=703 \pm 10 \mathrm{~K}$, (d) $\mathrm{N}_{2}$ at $\mathrm{T}_{\mathrm{s}}=1048 \pm 25 \mathrm{~K}$, and (e) $\mathrm{N}_{2}$ at $\mathrm{T}_{\mathrm{s}}=1128 \pm 25 \mathrm{~K}$. The lines at $1326 \mathrm{~cm}^{-1}$ and $1646 \mathrm{~cm}^{-1}$ are provided to guide the eye.

Figure 6. XPS survey spectra of all plasma-treated samples (top), N1s (top inset) and C1s core

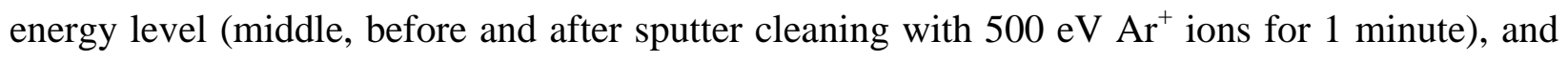
plasmon loss (bottom, no sputter cleaning) spectra of DND samples treated in single gas plasma: (a) original detonation nanodiamond (DND) powder, and DND exposed to microwave gas plasma of (b) $\mathrm{H}_{2}$ at $\mathrm{T}_{\mathrm{s}}=923 \pm 10 \mathrm{~K}$, (c) $\mathrm{O}_{2}$ at $\mathrm{T}_{\mathrm{s}}=703 \pm 10 \mathrm{~K}$, (d) $\mathrm{N}_{2}$ at $\mathrm{T}_{\mathrm{s}}=1048 \pm 25 \mathrm{~K}$, (e) $\mathrm{N}_{2}$ at $\mathrm{T}_{\mathrm{s}}=1128 \pm 25 \mathrm{~K}$, (f) $\mathrm{H}_{2} / \mathrm{N}_{2}$ at $\mathrm{T}_{\mathrm{s}}=1128 \pm 25 \mathrm{~K}$, and $(\mathrm{g}) \mathrm{H}_{2} / \mathrm{O}_{2}$ plasma, $\mathrm{T}_{\mathrm{s}}=1033 \pm 25 \mathrm{~K}$. 


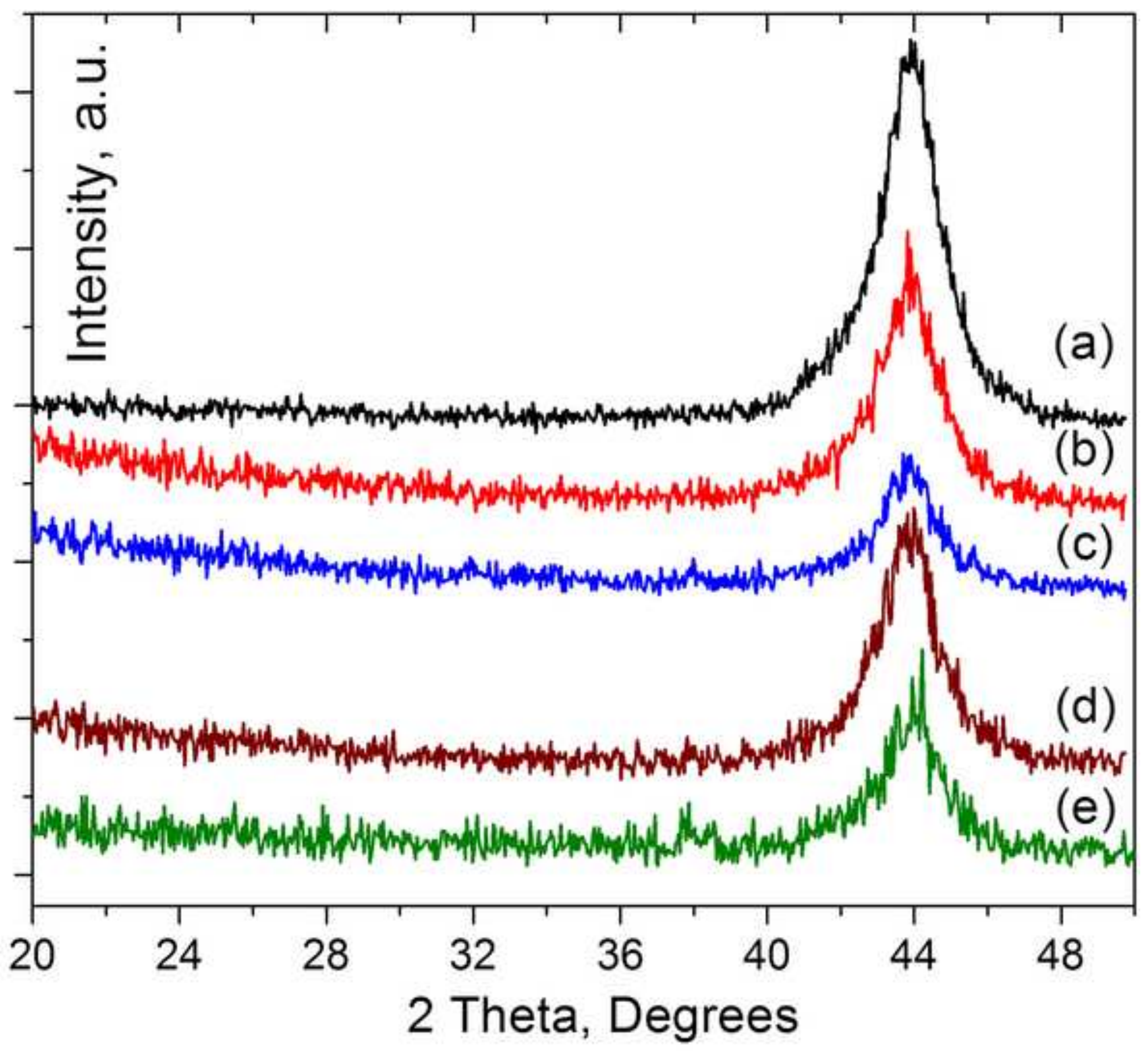




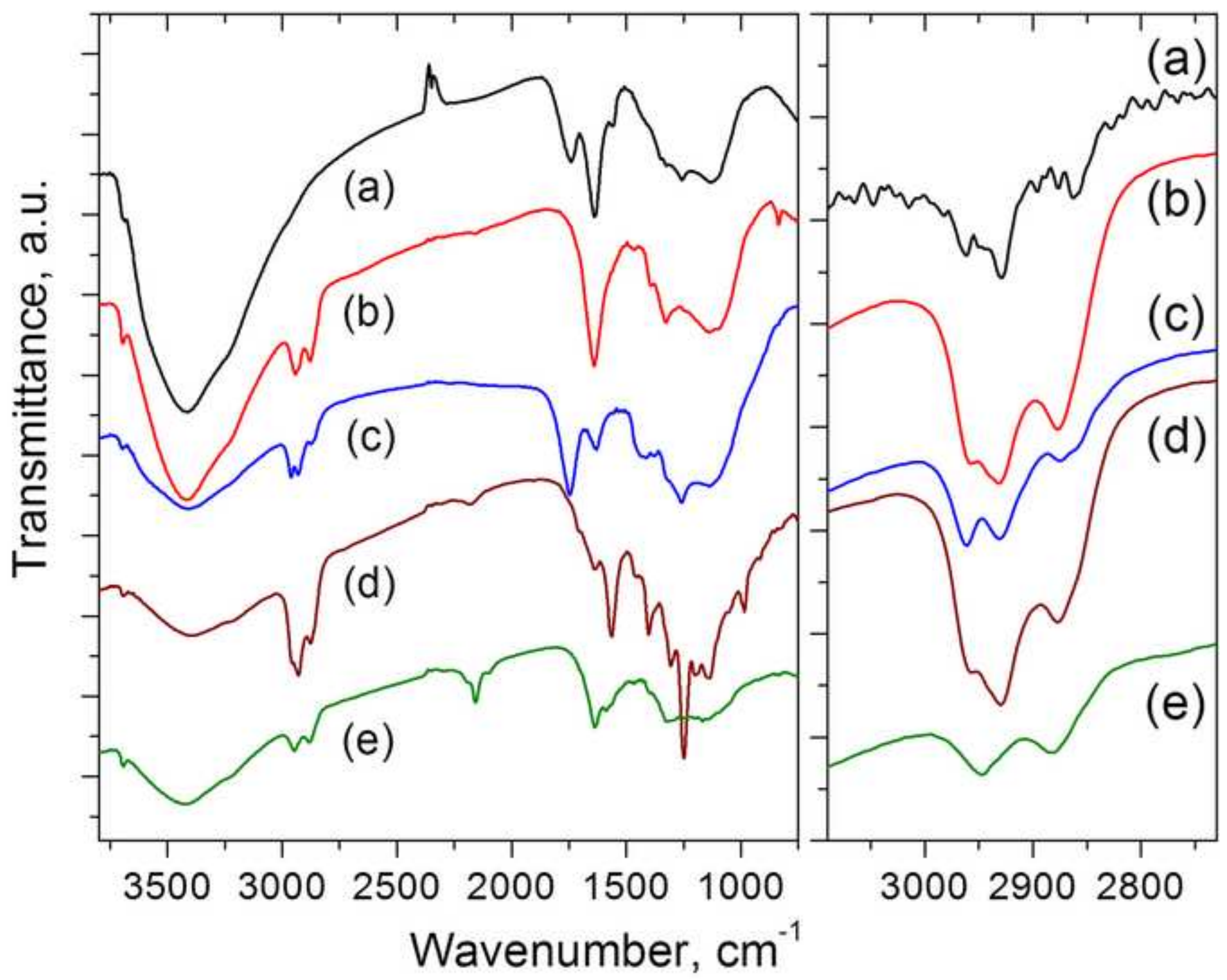




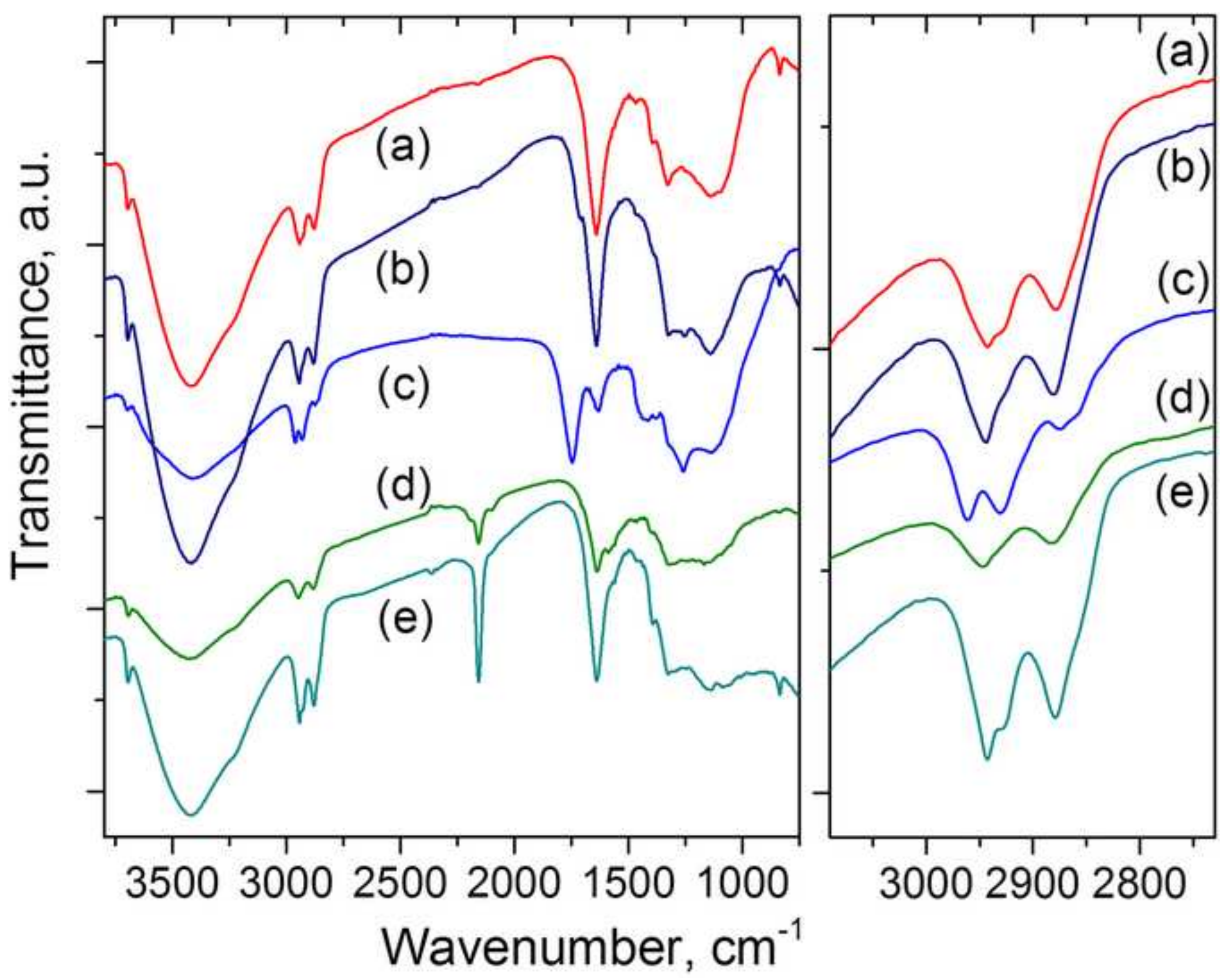



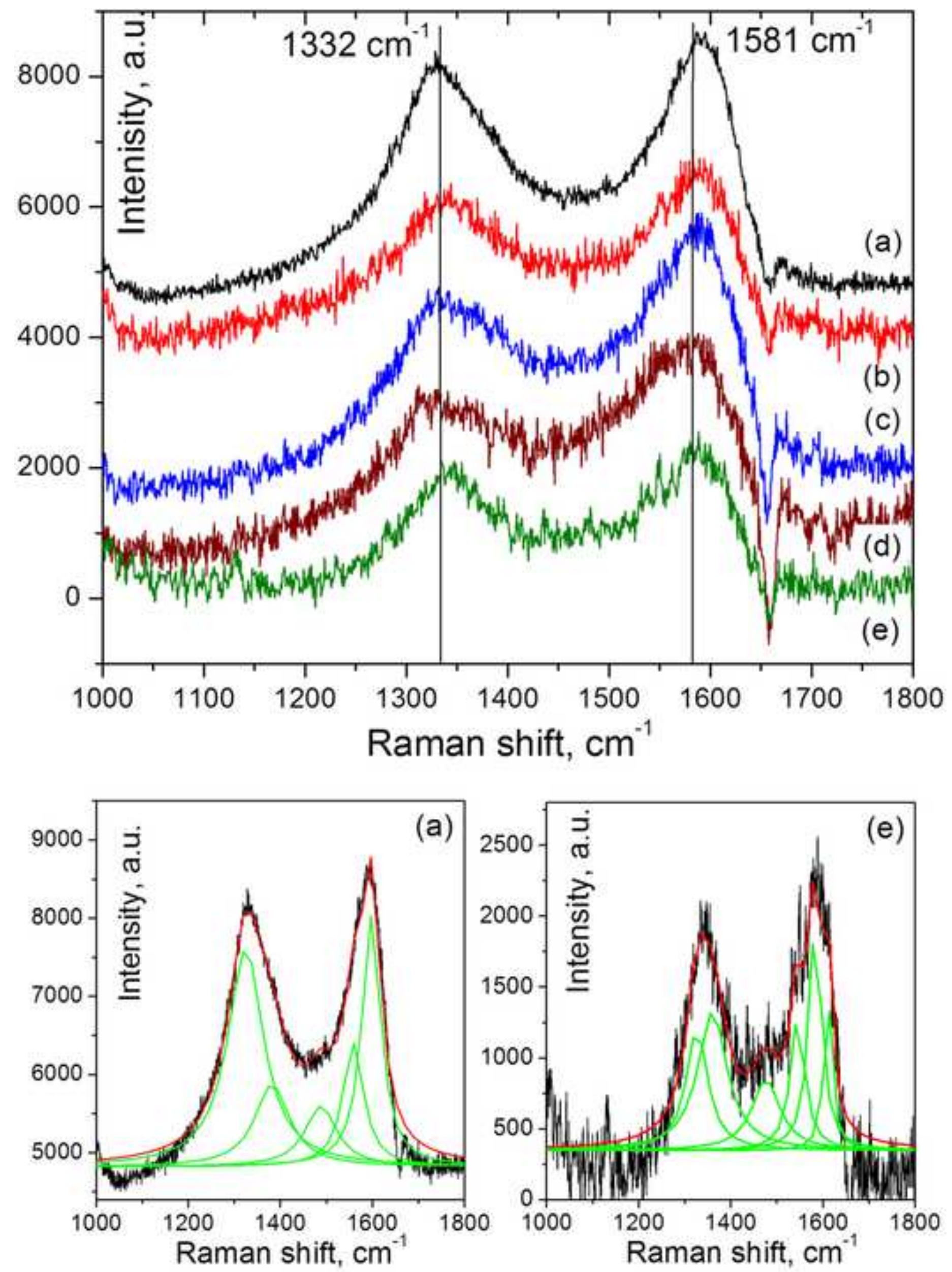


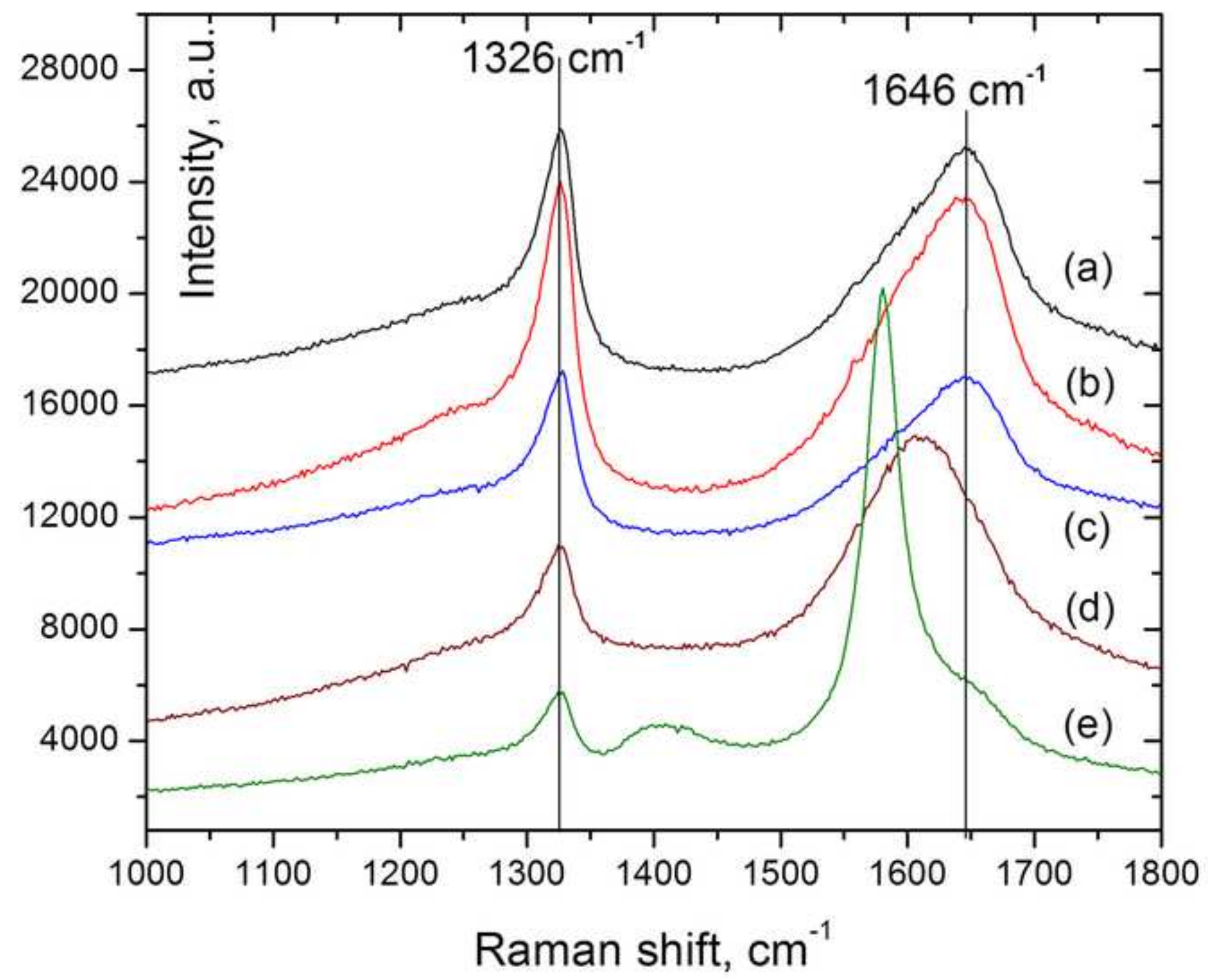



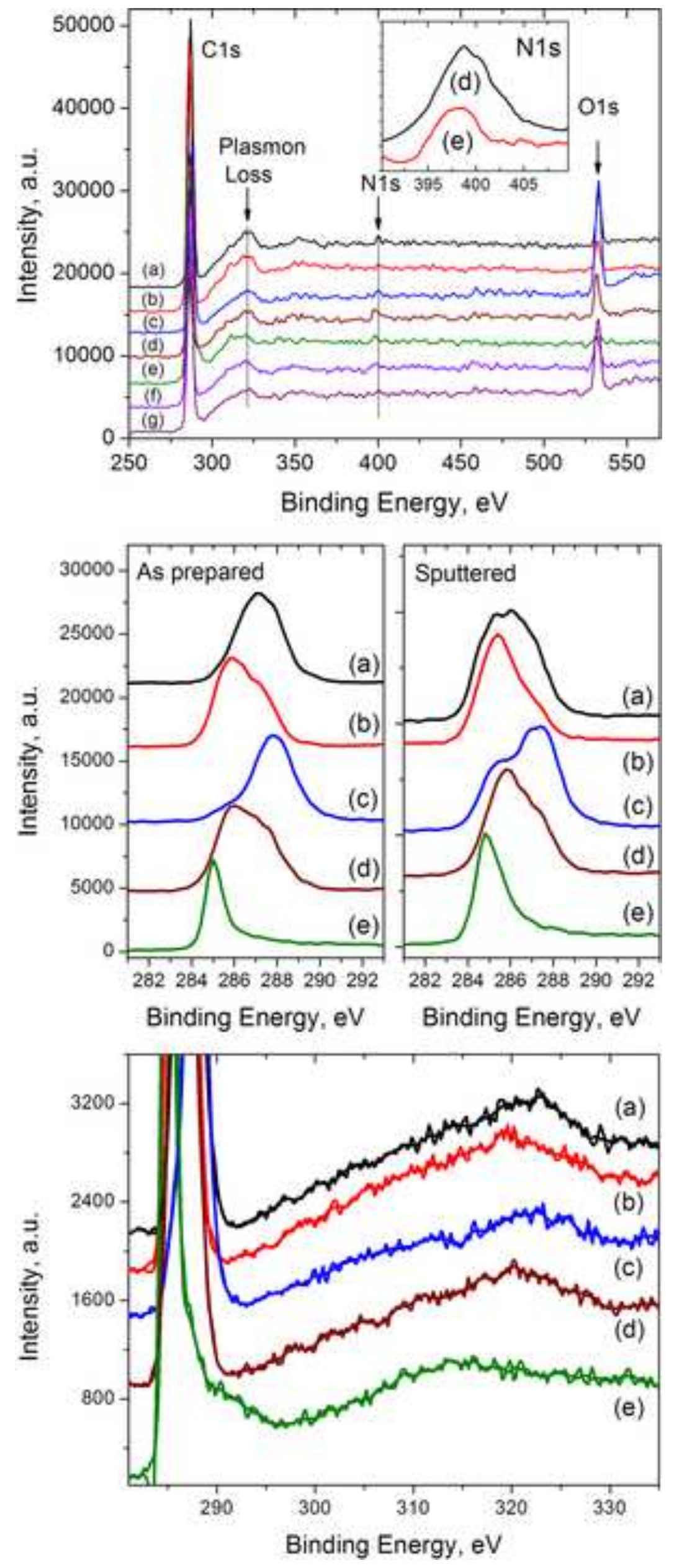
Microwave gas plasma

Nanodiamond

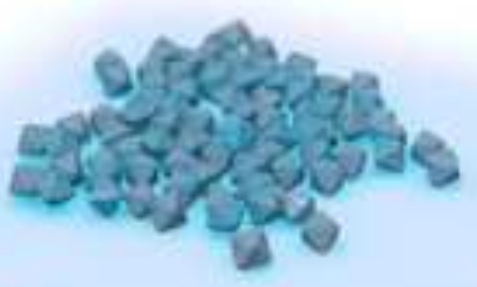

$\mathrm{H}_{2} / \mathrm{O}_{2}$

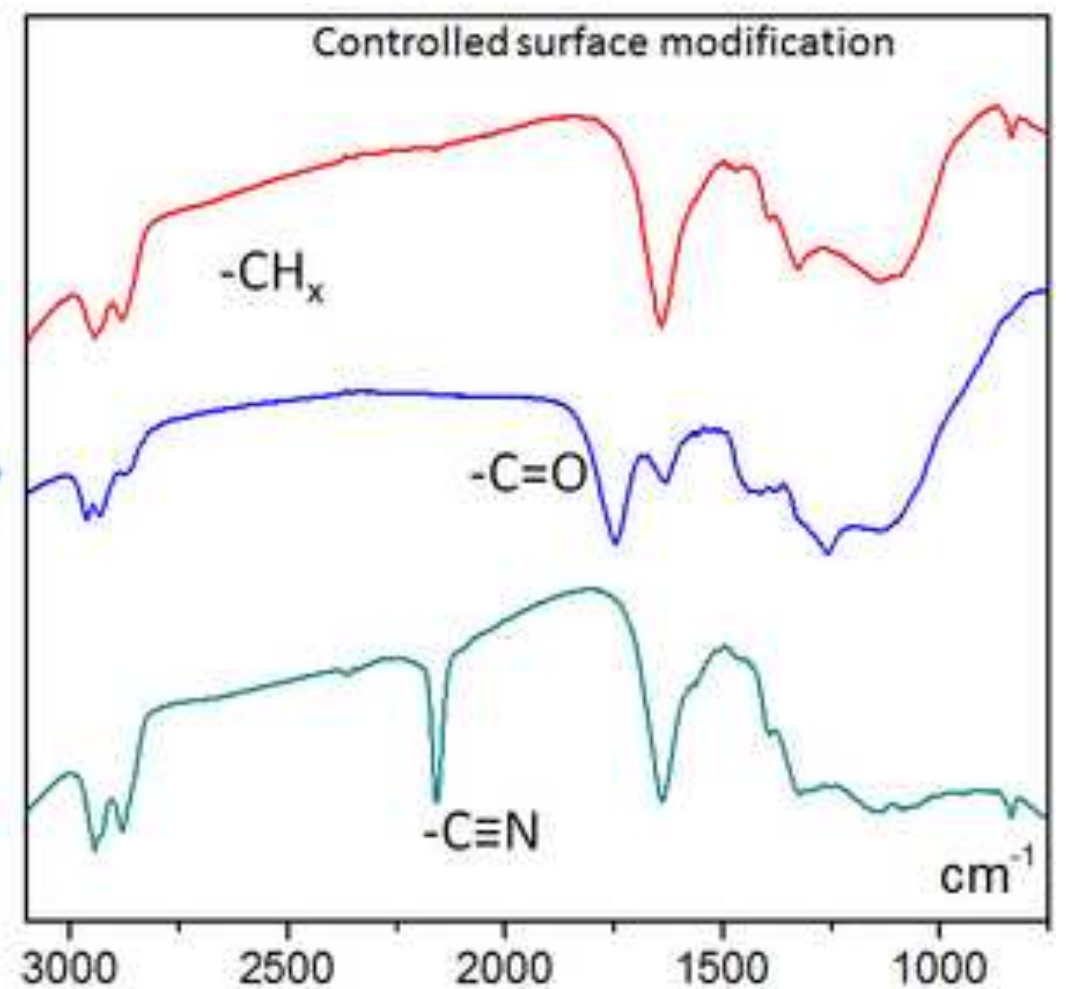

